\title{
Color discrimination on the border of photopic/mesopic vision
}

\begin{abstract}
The human eye is most sensitive to the wavelength region $555 \mathrm{~nm}$, with decreasing light intensity is shifted the sensitivity of the human eye to shorter wavelengths. Subjective evaluation of observers (Farnsworth-Munsell 100 Hue test and a set of color chips) were performed under seven luminous levels on mesopic and photopic luminance level, which have been achieved application of proof car foils with different luminous transmission on polymethylmethacrylate plates. A select group of observers was divided according to FM 100 Hue Test to the categories superior (The total overall error score to 19) and average (The total overall error score to 100) by the total overall error score. For the evaluation of the observers was chosen set of color samples defined by National Coil Coaters Association (A prismatic display of Measured color difference). They are colorful papers square chips with the measured color difference with 1 or 5 units (progressively according the axis $L+a+b+, L-, a-, b$-) from the center chip (16 center chip, total of 96 samples). Of the evaluated data it was found that the evaluation of color differences on chips with small color difference $(D E=1)$ is the distinction these chips possible even at 1 lux. From this luminous lighting increased differentiation between trials observers. For chips with a larger color difference $(D E=5)$ were the differences in evaluation observers at all high luminance levels.
\end{abstract}

Keywords: Colorimetry, vision, color discrimination, psychology, color difference

\section{Introduction}

The human eye is a highly specialized and complex organ providing recognition of objects, movement, light and color. Among the parts, that ensure the creation and processing of visual stimuli include the retina, where there are two types of light sensitive cells, photoreceptors (rods, cones), the visual pathway and visual cortical center. The human eye is able to perceive the part of the electromagnetic spectrum in the wavelength range 380-780 $\mathrm{nm}$. Most sensitive is the human eye to the wavelength region of $550 \mathrm{~nm}$.

What, colors we see and perceive, are extensively influenced by the intensity of light. Depending on the intensity of light we are talking about photopic, scotopic and mesopic vision. At photopic vision they are applying three types of cones, each they are having a different spectral sensitivity (cone L $564 \mathrm{~nm}, \mathrm{M}$ and S $534 \mathrm{~nm} 420 \mathrm{~nm}$ ). The maximum luminous efficiency at photopic vision $683 \mathrm{~lm} / \mathrm{W}$ is achieved at a wavelength of $555 \mathrm{~nm}$ [1]. At scotopic vision is applying second types of photoreceptors, rods. This type of photoreceptor is more sensitive to light than the second type photoreceptors and allows the perception of objects with a brightness of less than $0,001 \mathrm{~cd} . \mathrm{m}^{-2}$. The maximum luminous efficiency of $1700 \mathrm{Im} . \mathrm{W}^{-1}$ at scotopic vision is achieved at a wavelength of $507 \mathrm{~nm}$. Mesopic vision is called an area of transition between photopic and scotopic vision. Vision in this region is participates both types of light-sensitive cells. The transition between these areas is called as Purkinje shift [2]. On the basis of this shift at a lower light intensity appear to be a lighter blue objects than red objects (see on Fig. 1).

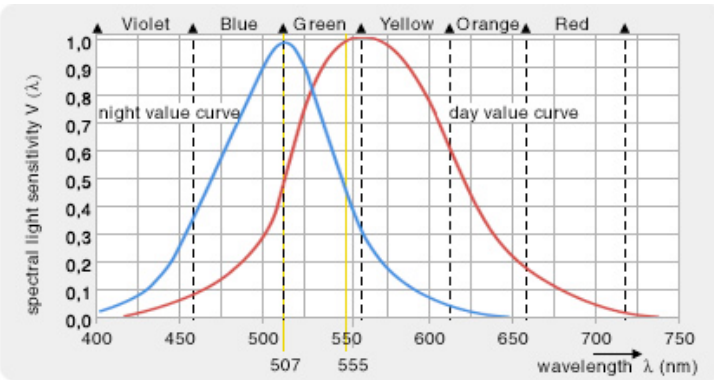

Fig.1. Spectral light sensitivity [3]

\section{Materials and methods}

For the evaluation of the observers was chosen set of color samples defined by National Coil Coaters Association (A prismatic display of Measured color difference). The set are formed from colorful papers square chips with the measured color difference with 1 or 5 units from the center chip $(\Delta \mathrm{E}=1$ and $\Delta \mathrm{E}=5)$ progressively according the axis $\mathrm{L}+$ $a+b+, L-, a-, b-$. The set are formed 16 center chips, for each one of chips are belonging 6 color samples.

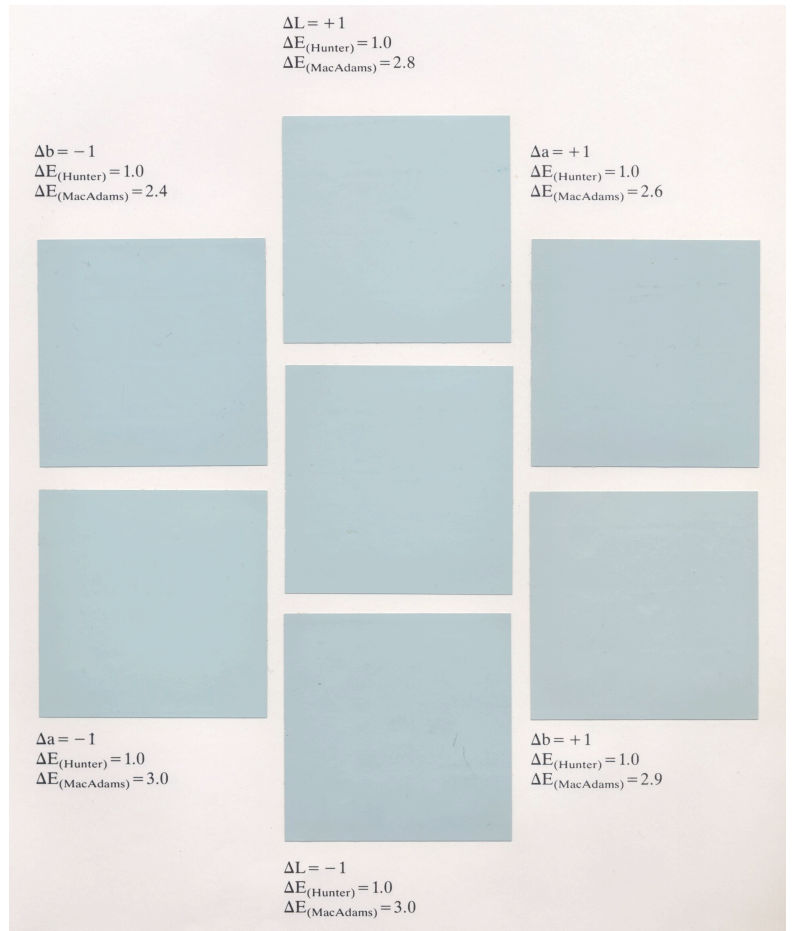

Fig.2. The center chips no. 3 with 6 samples $(\Delta \mathrm{E}=1)$

This set of samples was measured objectively using the remission spectrophotometer HunterLab Miniscan XE Plus with measuring geometry of 45 grad using a light source D65 and complementary observer. This measurement was used for obtaining the color coordinates $L$ *, $a$ * and $b$ * and the spectral reflectance. 
Subjective evaluation of observers (Farnsworth-Munsell 100 Hue test and a set of color chips) were performed in viewing cabinet AtelierTechnik color by using D65 (color temperature was $6504 \mathrm{~K}$ ) illumination simulating daylight under seven luminous levels on mesopic and photopic luminance border. Which have been achieved application of proof car foils with different luminous transmission on polymethylmethacrylate plates (transmission of light $16 \%$ and $6 \%$ ). Table 1 summarized the measured levels of illuminance and luminance. This viewing cabinet was in a dark room.

Table 1. Illuminance and luminance levels in viewing cabinet

\begin{tabular}{|c|c|c|}
\hline Label & Illuminance (lux) & $\begin{array}{c}\text { Luminance } \\
\left(\text { cd. }^{-2}\right)\end{array}$ \\
\hline 0 & 1405,9 & 380 \\
\hline 1 & 217,46 & 60 \\
\hline 2 & 38,59 & 10,6 \\
\hline 3 & 6,11 & 1,6 \\
\hline 4 & 1,42 & 0,4 \\
\hline 5 & 0,39 & 0,1 \\
\hline 6 & 0,11 & 0,03 \\
\hline
\end{tabular}

The evaluation of color difference between standard (center chip) and samples was made by Grey Scale for assessing change in color conforming to BS EN 2015 A02: 1995 specification from company SDC Enterprises Limited. Observers were determined by means of grey scale level, which according to them approximating color difference sample and center chip.

To convert from grey scale to visually perceived color difference was used equation [4] (1):

$$
d V=-1.078+23.56 e^{-G S / 1.709}
$$

where GS is level of grey scale.

Subjective evaluation was attended by 14 observers ( 10 women and 4 men), which were born between 1986 and 1992. According to the total error scores using the FM test subjects were categorized into superior and average.

Total evaluation of color samples evaluated 47.040 assessments, ie. individual observer has performed 3.360 individual assessments.

The STRESS index [5] has been employed to measure the goodness of the predictions made by each tested colordifference formulas with respect to the whole set of results in our work. The STRESS can be applied to the conventional color-difference domain, where the main goal is to achieve a color-difference formula whose results correspond to visually perceived color differences, for a given set of $\mathrm{i}=1 ; \ldots ; \mathrm{N}$ color pairs, under fixed illumination and viewing conditions. Specifically, for the color pair i, we can designate the visually perceived color difference (i.e., the response of the human visual system) by $\Delta V_{i}$, and the computed color difference (i.e., the result provided by a color-difference formula) by $\Delta E_{i}$, defining a normalized percentage STRESS index [6] as follows:

$$
\text { STRESS }=100 \sqrt{\frac{\sum\left(\Delta E_{i}-F \Delta V_{i}\right)^{2}}{\sum \Delta E_{i}^{2}}}
$$

In our experiment was 96 pairs at each luminance level (i.e. 16 color charts $\times 6$ samples $=96$ color pairs $)$. The $\Delta V_{i}(i=$ $1, \ldots, 96)$ values in our STRESS computations were the average of true $\Delta \mathrm{V}$ values reported by our 14 observers. Low STRESS values (always in the range 0-100) indicate better performance of a color-difference formula. For each observer, intra-observer variability was computed as the average of STRESS values of each one of the 5 replications made by this observer with respect to the robust average of the 5 replications (lower and higher value was rejected, rest three were used for computing of average value), while inter-observer variability was computed as the STRESS value considering the average result of the 5 replications of this observer with respect to the average results of all 14 observers. Final intra- and inter-observer variability in our experiment were defined as the robust average intra- and inter-observer variability STRESS values from the 14 observers, respectively.

Generally were tested several formulas, such as CIE76 [7] (3), CMC [8, 9] (4), and the recent CIEDE2000 [10] (5) formula, which are mainly used in industrial applications:

$$
\Delta E^{*}=\sqrt{(\Delta L *)^{2}+\left(\Delta a^{*}\right)^{2}+\left(\Delta b^{*}\right)^{2}}
$$

where $\Delta \mathrm{L}^{*}$ is difference in lightness, $\Delta \mathrm{a}^{*}$ - difference in redness-greenness, $\Delta b^{*}$ - difference in yellownessblueness.

$$
\Delta E_{C M C}=\sqrt{\left(\frac{\Delta L *}{l S_{L}}\right)^{2}+\left(\frac{\Delta C *}{c S_{C}}\right)^{2}+\left(\frac{\Delta H^{*}}{S_{H}}\right)^{2}}
$$

where $\Delta \mathrm{C}^{*}$ is difference in chroma, $\Delta \mathrm{H}^{*}$ is difference in hue, $S_{L}, S_{C}, S_{H}-$ are scaling factors.

$$
\Delta E_{00}=\sqrt{\left(\frac{\Delta L}{k_{L} S_{L}}\right)^{2}+\left(\frac{\Delta C^{*}}{k_{C} S_{C}}\right)^{2}+\left(\frac{\Delta H^{*}}{k_{H} S_{H}}\right)^{2}+R_{T}\left(\frac{\Delta C^{*}}{k_{C} S_{C}}\right)\left(\frac{\Delta H^{*}}{k_{H} S_{H}}\right)}
$$

where $R_{T}$ is rotation factor.

\section{Results and discussion}

Best performance (highest predictive value) was achieved equation CIEDE2000 by luminance interval 380$0,4 \mathrm{~cd} . \mathrm{m}^{-2}$. In deep mesopic luminance levels appear better CMC color difference formula. Lowest performance (lowest predictive value) was achieved equation CIELAB (tab. 2).

The STRESS index allows a statistical judgment of the prediction performance of color-difference formulas. To determine whether two formulas $\Delta E a$ and $\Delta E b$ are significantly different, one has to take the squared ratio of the corresponding STRESS values $\mathrm{Sa}$ and $S b$ on the same test data [11]:

$$
S_{r}=\frac{S_{a}^{2}}{S_{b}^{2}} \quad S_{a}>S_{b}
$$

Let $F$ be the value corresponding to $F$-distribution with $n-1$ degrees of freedom (number of test color pairs minus one) and desired confidence level $95 \%$. If $S_{r}$ lies outside the confidence interval $[F, 1 / F]$, the predictions of the two color difference formulas are significantly different. For example to compare CIELAB and CIEDE2000 color difference formula on our dataset at luminance level $380 \mathrm{~cd} . \mathrm{m}^{-2}$ with a $95 \%$ confidence level, one would compute:

$$
S_{r}=(20,17)^{2} /(9,67)^{2}=4,35
$$


This squared ratio is (a) greater than one, which indicates that the CIEDE2000 performs better than CIELAB, and lies (b) outside the $95 \%$ confidence interval $[0,56,1.79]$, meaning that this difference is statistically significant [6].

In other evaluation we can compare CIEDE2000 and CMC (1.1) color difference formulas on our dataset at luminance level $0,03 \mathrm{~cd} . \mathrm{m}^{-2}$ with a $95 \%$ confidence level, resulting squared ratio $S_{r}=1,48$. Based on that (a) CMC (1:1) performs better than CIEDE2000 and lies (b) inside the $95 \%$ confidence interval $[0,56,1.79]$, meaning that this difference is statistically insignificant. Interestingly, the STRESS difference between CIEDE2000 and the CMC (1:1) color difference formula is statistically not significant for all other investigated luminance levels according to the F-test. Beside that CMC (2:1) color difference formula was not significantly better than CIELAB due to increased tolerance in lightness, which is effective for textured samples, but in our experiment with smooth surface of tested samples was second worse formula. This results confirm general recommendations of setup of this color difference equation.

Table 2. STRESS index comparison.

\begin{tabular}{|c|c|c|c|c|}
\hline $\begin{array}{c}\text { Luminance } \\
\left(\mathrm{cd} . \mathrm{m}^{-2}\right)\end{array}$ & CIELAB & $\begin{array}{c}\text { CMC } \\
\mathbf{( 1 : 1 )}\end{array}$ & $\begin{array}{c}\text { CMC } \\
\mathbf{( 2 : 1 )}\end{array}$ & $\begin{array}{c}\text { CIE } \\
\text { DE00 }\end{array}$ \\
\hline 380 & 20,17 & 9,96 & 16,24 & $\mathbf{9 , 6 7}$ \\
\hline 60 & 19,92 & 9,89 & 16,32 & $\mathbf{9 , 6 5}$ \\
\hline 10,6 & 19,9 & 10,11 & 16,9 & $\mathbf{9 , 1 9}$ \\
\hline 1,6 & 19,96 & 10,14 & 16,9 & $\mathbf{9 , 2}$ \\
\hline 0,4 & 19,32 & 9,91 & 18,46 & $\mathbf{8 , 3 2}$ \\
\hline 0,1 & 18,88 & $\mathbf{8 , 6 9}$ & 18,55 & 8,78 \\
\hline 0,03 & 17,87 & $\mathbf{7 , 3}$ & 19,73 & 8,89 \\
\hline
\end{tabular}

The decreasing of luminance levels during visual assessment of color differences between central sample and other samples in specific directions of color difference (sample is lighter, darker, yellower, redder, greener or bluer than standard) has influence on recognition of adequate size of color difference. Using estimates linear regression software of Statsoft Statistica 8.0 obtained two linear equations and the breakpoint. Break point indicates the intensity of light at which the transition occurs between the so-called differentiations adequate and non-adequate visual evaluation of samples color difference.

The graph on Figures 3 and 4 shows that break point of visual assessment lies on luminance level $1 \mathrm{~cd} . \mathrm{m}^{-2}$ independently on shade and direction of color difference of evaluated sample.

To illustrate the fact that there are many reasonable parameter combinations, figure 5 shows the color difference assessment of deep pink colors. The evaluation of set of samples with greater color difference (generally $\Delta \mathrm{E}=5$ in HunterLab color space) was affected by troubles with transformation of color difference into lightness difference of used grey scale for evaluation of color change. The graph on Figure 5 shows high variability of visual assessment and position of break point at luminance level $0,1 \mathrm{~cd} . \mathrm{m}^{-2}$. Similar situation, but standard with deep pink color and color difference of evaluated sample in red direction shows beside increased variability shift of break point position on luminance level $4 \mathrm{~cd} \cdot \mathrm{m}^{-2}$. Based on that we can speculate that Purkinje shift is mostly important for evaluation of greater color differences than for small color differences. Probable source of this result is in visual transition of color difference into lightness difference, which is affected by increased meaning of rod sensitivity, which is shifted to shortest wavelength in comparison to luminous effectiveness of cones. Therefore assessment of color difference $\Delta \mathrm{E}=5$ into blue direction is affected at significantly lower luminance level in comparison to same size of color difference into red direction.

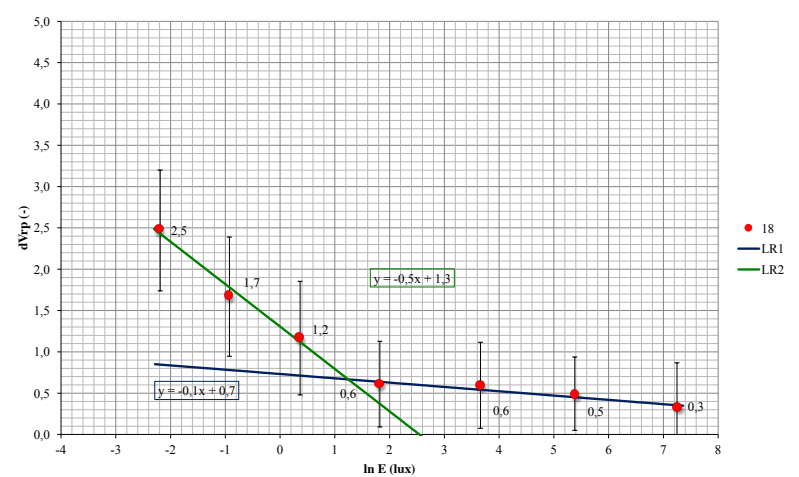

Fig.3. Deep pink sample $\Delta \mathrm{E}=1$ bluer

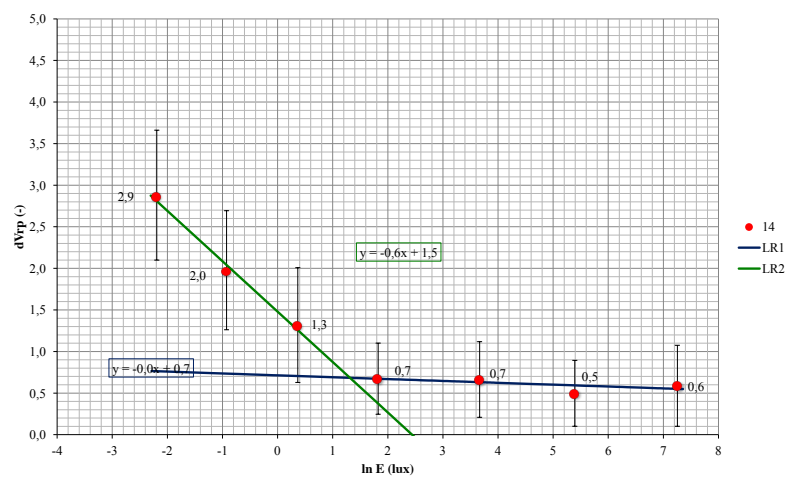

Fig.4. Pale blue sample $\Delta \mathrm{E}=1$ redder

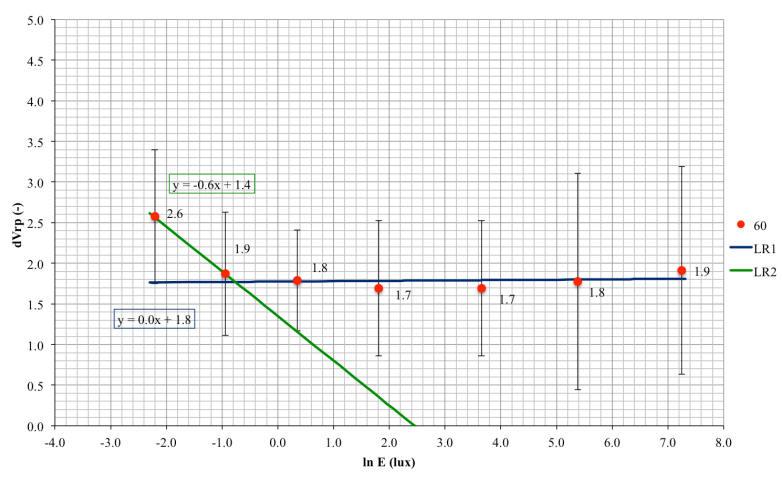

Fig.5. Deep pink sample $\Delta \mathrm{E}=5$ bluer

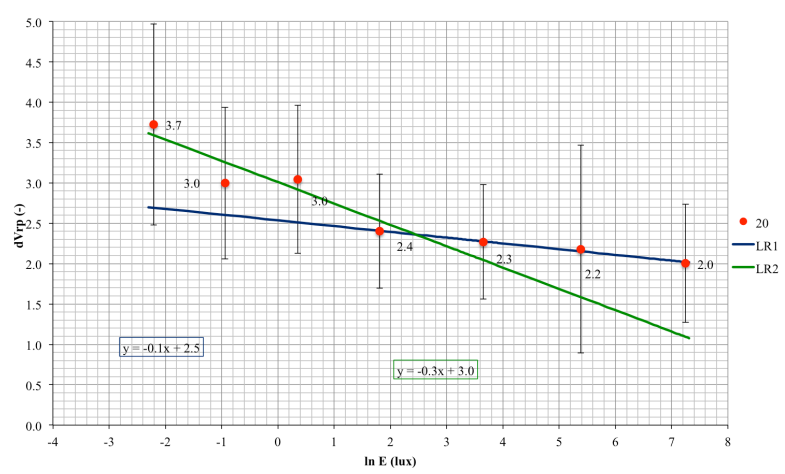

Fig.6. Pale blue sample $\Delta \mathrm{E}=5$ redder 


\section{Conclusion}

Any of the selected observers didn't have experience with the visual evaluation of the samples. On this basis, it was established five repetitions assessment. For the final evaluation was then used an average of three assessment, i.e. the minimum and maximum specified value of the gray scale was removed from the calculation. Because it was a subjective assessment, individual, every observer evaluated differently. With decreasing light intensity was varied using a gray scale range. The objective of this evaluation was primarily how the observer is able to repeat the assessment of color samples, ie. the individual assessment conformity.

Based on the evaluated data it was found that in samples with small color difference is the breaking point, calculated from the individual assessment observers, at interval $0,9-1,6 \mathrm{~cd} \cdot \mathrm{m}^{-2}$. For samples with a large color difference is not discernible break point. The results show also that a group of observers is consistent, ie. the assessment of individual observers didn't differ significantly from the average. The value of the stress with decreasing luminance levels decreased. Therefore this indicates greater consistency between observers.

\section{REFERENCES}

[1] Hunter, R.S., Harold, R.W. The measurement of appearance, John Willey \& Sons, New York 1987, sec. edition.

[2] G. Wyszecki and W. S. Stiles, Color Science: Concepts and Methods, Quantitative Data and Formulae, John Wiley and Sons, New York, 1982.

[3] KLAASEN, Martin. Light Talk: a week in the life of light Season 6 [online]. [cit. 16.4.2015]. Dostupný na WWW: http://lighttalk.via-verlag.com/2013/09/basics-people/

[4] Vik M.,"Colour difference formula evaluation on LCAM textile data, Vlakna a Textil, 10 (3, 126-129, 2003.
[5] P. A. García, R. Huertas, M. Melgosa, and G. Cui. Measurement of the relationship between perceived and computed color differences. Journal of the Optical Society of America A, 24(7):1823- 1829, 2007.

[6] M. Melgosa, R. Huertas, and R. S. Berns. Performance of recent advanced color-difference formulas using the standardized residual sum of squares index. Journal of the Optical Society of America A, 25(7):1828-1834, 2008.

[7] CIE Pub. 15.2, Colorimetry. 2nd Ed. p 33 (Note 9). Vienna: CIE Central Bureau; 1986.

[8] Clark, F.J.J., McDonald,R., Rigg, B.: J. Soc. D. Col. 100 (1984), 128-132.

[9] Vik M. Colour-difference formulas study, Texsci 2000; Technical University Liberec; Czech Republic; 12 June 2000 through 14 June 2000, ISBN 80-7083-409-9.

[10] M. R. Luo, G. Cui, and B. Rigg, The development of the CIE 2000 colour-difference formula: CIEDE2000, Color Res. Appl. 26, 340-350 (2001).

[11] Lissner, I., Urban, P.: Improving Color-Difference Formulas Using Visual Data, CGIV 2010 Final Program and Proceedings, 2010 Society for Imaging Science and Technology, 483-488
Authors:

doc. Ing. Michal Vik, Ph.D., Technická univerzita v Liberci, Fakulta textilní, Laboratoř Měření Barevnosti a Vzhledu, Studentská 2, 46117 Liberec, Czech Republic, e-mail: michal.vik@tul.cz

Ing. Martina Viková, PhD., Technická univerzita v Liberci, Fakulta textilní, Laboratoř Měřní Barevnosti a Vzhledu, Studentská 2, 46117 Liberec, Czech Republic, e-mail: martina.vikova@tul.cz

Ing. Marcela Pechová, Technická univerzita v Liberci, Fakulta textilní, Laboratoř Měření Barevnosti a Vzhledu, Studentská 2, 46117 Liberec, Czech Republic, e-mail: marcela.pechova@tul.cz 